\title{
INCIDENTE DE RESOLUÇÃO DE DEMANDAS REPETITIVAS: UM BREVE ESTUDO SOBRE OS CONCEITOS DE SEGURANÇA JURÍDICA E ISONOMIA
}

\author{
Gabriela Oliveira Freitas ${ }^{1}$
}

\begin{abstract}
Resumo
O presente trabalho apresenta uma crítica ao Incidente de Resolução de Demandas Repetitivas, a partir da revisitação dos conceitos de isonomia e segurança jurídica, que foram considerados pelo legislador como justificativas para a criação dessa técnica. Adotando a Teoria Neoinstitucionalista do Processo, demonstrou-se que segurança jurídica não significa assegurar a previsibilidade das decisões judiciais e que isonomia não consiste em julgar casos idênticos de forma idêntica. Utilizar-se-á a pesquisa bibliográfica e o método dedutivo, e, por fim, como procedimento técnico a análise temática, teórica e interpretativa.
\end{abstract}

Palavras-chave: Incidente de Resolução de Demandas Repetitivas; Isonomia; Segurança Jurídica; Estado Democrático de Direito

\section{REPEAT DEMANDS RESOLUTION INCIDENT: A BRIEF STUDY ON THE CONCEPTS OF LEGAL SECURITY AND ISONOMY}

\begin{abstract}
The present work presents a critique of the Incident of Resolution of Repetitive Demands, from the revisiting of the concepts of isonomy and legal security, which were considered by the legislator as justifications for the creation of this technique. Adopting the Neoinstitutionalist Theory of the Process, it was demonstrated that legal certainty does not mean ensuring the predictability of judicial decisions and that isonomy does not consist in judging identical cases in an identical way. Bibliographic research and the deductive method will be used, and finally, thematic, theoretical and interpretive analysis will be used as a technical procedure.
\end{abstract}

Keywords: Repeat Demands Resolution Incident; Isonomy; Legal Security; Democratic State

\section{INTRODUÇÃO}

O direito brasileiro vem seguindo uma clara tendência de valorização dos chamados precedentes judiciais, que, aos poucos, passou a ganhar força vinculante, com ainda maior

\footnotetext{
${ }^{1}$ Doutora, Mestre e Especialista em Direito Processual pela PUC Minas. Especialista em Filosofia e Teoria do Direito pela PUC Minas. Professora do Programa de Pós-Graduação Stricto Sensu em Direito da Universidade FUMEC. Professora de cursos de graduação e pós-graduação em Direito. Coordenadora-Adjunta do IMDP Instituto Mineiro de Direito Processual. Pesquisadora do INPEJ - Instituto Popperiano de Estudos Jurídicos. Assessora Judiciária do Tribunal de Justiça de Minas Gerais.

Email: profgabrielafreitas@gmail.com
}

Revista de Processo, Jurisdição e Efetividade da Justiça | e-ISSN: 2525-9814 | Encontro Virtual | 
destaque a partir da promulgação do novo Código de Processo Civil (Lei no 13.105, de 16 de março de 2015). Nesse sentido, há alguns anos, vem-se observando uma série de reformas legislativas que atribuíram uma maior força aos precedentes judiciais e súmulas de Tribunais Superiores, o que torna possível perceber uma grande influência (ainda que desordenada) do sistema da common law no direito brasileiro, configurando uma clara tendência de busca por padronização decisória. Por isso, muito tem se discutido acerca da relevância da utilização dos precedentes judiciais como forma de fundamentação dos provimentos jurisdicionais.

Assim, a partir do ideal de garantir segurança jurídica e isonomia aos jurisdicionados, a legislação brasileira, de 2004 em diante, passou a contar com diversos mecanismos de construção de precedentes judiciais, dentre os quais se destaca o recém-criado Incidente de Resolução de Demandas Repetitivas, objeto de estudo do presente artigo.

O Incidente de Resolução de Demandas Repetitivas consiste em mecanismo adotado pelo novo Código de Processo Civil (Lei no 13.105/2015), que permite o julgamento de casos por amostragem. Ou seja: a partir do julgamento de um caso concreto, define-se o tema da controvérsia e o Tribunal analisa a tese em discussão, que será, posteriormente, aplicada aos casos atuais e futuros.

Por meio da análise de tal técnica de julgamento, pode-se notar a intenção do legislador de estender o âmbito de aplicabilidade das decisões judiciais, fazendo com que o Judiciário, no menor número de vezes possível, tenha que se aprofundar na análise de questões similares, tornando-se mais eficiente quantitativamente por meio do estabelecimento de padrões a serem seguidos nos casos idênticos subsequentes, sob o argumento de preservação da isonomia, da celeridade, da estabilidade e da previsibilidade do sistema, visando a garantir a segurança jurídica.

Todavia, a crítica que aqui se pretende formular se baseia na equivocada compreensão do que seja essa almejada segurança jurídica e do que se entende por isonomia, buscando-se demonstrar que, apesar do discurso do legislador indicar que a segurança e a previsibilidade dos julgados seriam um benefício aos cidadãos, trata-se, em verdade, de técnica de dominação do povo pelo Estado, retrocedendo, assim, ao paradigma do Estado Social.

A partir da perspectiva do Estado Democrático de Direito, aqui compreendido como "não dogmático" (LEAL, 2013, p. 3), busca-se verificar se essa construção de precedentes, por meio do Incidente de Resolução de Demandas Repetitivas, representa um avanço ou 
retrocesso nos estudos da ciência processual e se apresenta compatibilidade com o direito processual democrático.

Para tanto, analisar-se-á, brevemente, o sistema de precedentes judiciais atualmente adotado no direito brasileiro, a fim de permitir uma melhor análise do procedimento adotado nos Incidentes de Resolução de Demandas Repetitivas. Em seguida, será realizada uma crítica a esta técnica de julgamento e aos seus efeitos por meio de uma revisitação do conceito de segurança apresentado por Thomas Hobbes e do conceito de isonomia desenvolvido por Rosemiro Pereira Leal.

A presente pesquisa justifica-se pela atualidade do tema, além de refletir problema configurado na prática jurídica.

Optou-se pela Teoria Neoinstitucionalista do Processo como marco teórico, uma vez que "propõe um giro importante na perspectiva tradicional, elaborando uma teoria de controle da decisão jurídica que torna despiciendas apelos à sapiência e às idiossincrasias sacerdotaisjudiciais" (LEAL; FANTINI, 2014, p. 23), sendo, por isso, adequada à proposta de trabalho, que busca uma análise dos verdadeiros objetivos da almejada estabilização da jurisprudência.

Para o presente estudo, utilizar-se-á ainda a pesquisa bibliográfica e o método dedutivo, partindo-se de uma perspectiva macro para uma concepção micro analítica acerca do tema ora em estudo e, por fim, como procedimento técnico a análise temática, teórica e interpretativa, buscando sugestão para a solução da questão destacada.

\section{BREVES CONSIDERAÇÕES SOBRE OS PRECEDENTES JUDICIAIS NO DIREITO BRASILEIRO}

A partir da Exposição de Motivos do Anteprojeto do Novo Código de Processo Civil, percebe-se que a elaboração de uma nova legislação processual teria por objetivo buscar solucionar problemas como a morosidade da atividade jurisdicional, por meio da simplificação dos procedimentos, sendo que tais objetivos também seriam atingidos pela aplicação dos entendimentos padronizados dos tribunais.

Veja-se:

(...) é oportuno ressaltar que levam a um processo mais célere as medidas cujo objetivo seja o julgamento conjunto de demandas que gravitam em torno da mesma questão de direito, por dois ângulos: a) o relativo àqueles processos, em si mesmos considerados, que, serão decididos conjuntamente; b) no que concerne à atenuação do excesso de carga de trabalho do Poder Judiciário - já que o tempo usado para 
decidir aqueles processos poderá ser mais eficazmente aproveitado em todos os outros, em cujo trâmite serão evidentemente menores os ditos "tempos mortos" (= períodos em que nada acontece no processo). (BRASIL, 2010).

Nesse novo texto processual, observa-se uma grande preocupação com a estabilização da jurisprudência, a partir de uma total vinculação dos provimentos jurisdicionais aos precedentes judiciais, como forma de simplificar o julgamento dos casos futuros, o que, por certo, não aproxima o provimento jurisdicional da perspectiva democrática, que deveria ser alcançada no novo Código (já que o principal objetivo do novo CPC deveria ser adequar o Processo às diretrizes constitucionais, como também prometido na Exposição de Motivos).

Percebe-se, desde já, que essa busca pela padronização decisória é mais um dos representativos dos "fetiches das urgencialidades", que acometem o legislador brasileiro e a dogmática jurídica, que muito se preocupa com a eficiência do Judiciário, no sentido de se alcançar provimentos jurisdicionais de forma rápida, ainda que, para isso, seja necessário desconsiderar o devido processo.

Tanto é que, logo ao começar a tratar do "Processo nos Tribunais e dos Meios de Impugnação das Decisões Judiciais", no Livro III (o último), o novo CPC já traz, imediatamente, a seguinte informação em seu art. 926: "os tribunais devem uniformizar sua jurisprudência e mantê-la estável, íntegra e coerente”, sem que, todavia, consiga esclarecer quais seriam os significados dos conceitos de estabilidade, integridade e coerência. $\mathrm{O}$ que, se pretende, em verdade, é tão somente, garantir que todos os julgadores e todos os tribunais adotem, diante da similitude dos fatos, resultados idênticos para situações idênticas. Ou seja: a pretensão consiste na consagração do método indutivo para garantir decisões judiciais idênticas.

Continuando em tal propósito, prossegue o novo texto processual:

Art. 927. Os juízes e os tribunais observarão:

I - as decisões do Supremo Tribunal Federal em controle concentrado de constitucionalidade;

II - os enunciados de súmula vinculante;

III - os acórdãos em incidente de assunção de competência ou de resolução de demandas repetitivas e em julgamento de recursos extraordinário e especial repetitivos;

IV - os enunciados das súmulas do Supremo Tribunal Federal em matéria constitucional e do Superior Tribunal de Justiça em matéria infraconstitucional;

V - a orientação do plenário ou do órgão especial aos quais estiverem vinculados.

\footnotetext{
${ }^{2}$ Rosemiro Pereira Leal critica o "fetiche pela Justiça Rápida", apontando que a almejada "velocidade pode ser aumentada pela supressão do processo e, até mesmo, do procedimento, com a altaneira supremacia da jurisdição" (LEAL, Rosemiro Pereira. Teoria Geral do Processo: Primeiros Estudos. Rio de Janeiro: Forense, 2014, p. 233)
} 
Por meio de tal dispositivo legal, percebe-se o funcionamento desse novo sistema adotado no direito brasileiro: a partir da escolha da demanda representativa da controvérsia, todos os processos individuais terão como resultado aquele adotado no julgamento paradigma. Então, a decisão proferida nestes procedimentos destinados à construção de precedentes será vinculante para todos os juízes e atingirá todos os interessados, inclusive os litigantes futuros. Desse modo, busca-se identificar as questões comuns a todas as ações isomórficas, que serão julgadas a partir de um processo individual tomado como paradigma/amostra.

De uma análise dos mecanismos de construção de precedentes judiciais existentes no Direito Brasileiro, percebe-se que houve uma clara influência de institutos do sistema da common law e também do Musterverfarhen do Direito Alemão. Todavia, também é possível perceber que essa influência se deu sem aprofundamento teórico, o que ocasiona o problema de ausência de compatibilidade dos estudados procedimentos com os preceitos do Estado Democrático de Direito.

O que atualmente se verifica no direito do Brasil, que muitos chamam de aproximação do common law, é que a própria legislação vem tornando a jurisprudência fonte primária do direito, criando "procedimentos de sumarização da cognitividade baseados em técnicas de estandardização do direito, em que o seguimento à jurisprudência dominante é o fio condutor no processo de resolução de conflito" (FARIA, 2012, p. 84).

Porém, como aponta Dierle Nunes, "temos muito a aprender com a tradição do common law antes de nos valer de seu modo de aplicação, de forma completamente atabalhoada e mecânica, como os Tribunais e juízes brasileiros vêm, com recorrência, fazendo" (NUNES, 2012, p. 263).

Nesse contexto, Gustavo de Castro Faria também tece crítica semelhante a tal tendência brasileira:

\footnotetext{
a legislação processual vem seguindo uma direção que, numa ensandecida busca pela celeridade, tem como pano de fundo uma teorização antidemocrática que transforma o procedimento cognitivo-decisório num jogo de subsunção dos conflitos de interesses à razão jurisprudencial, a ser aplicada de forma apriorística, inquestionável e intransigente, transformando os casos concretos 'em tese', solucionados pela aplicação de precedentes reveladores do entendimento cristalizado pelos órgãos jurisidicionais. (FARIA, 2012, p. 70).
}

Como destaca Dierle Nunes, não existe, no Brasil, uma teoria idônea dos precedentes, ocorrendo uma formação equivocada de padrões decisórios e uma preocupante aplicação 
mecânica desses padrões pelos julgadores do primeiro e segundo grau” (NUNES, 2011, p. 81 - No mesmo sentido, informa Hermes Zaneti Junior que, apesar da dependência dos precedentes criada na tradição de civil law, "como mostram as decisões dos juízos que cada vez mais fazem referência a precedentes, inexiste nesta uma teoria dos precedentes" (ZANETI JUNIOR, 2016, p. 21).

Apesar da inexistência teórica sobre o tema, a questão vem sendo bem aceita pela prática jurídica, o que representa, desde já, um problema ante a ausência de análise crítica desse sistema de precedentes.

\section{NOÇÕES SOBRE O INCIDENTE DE RESOLUÇÃO DE DEMANDAS REPETITIVAS}

Seguindo a tendência já demonstrada anteriormente por meio dos recursos repetitivos, o novo CPC estende a possibilidade de litigância serial a todos os tribunais, por meio do Incidente de Resolução de Demandas Repetitivas, que se encontra previsto nos artigos 976 a 987 do novo Código de Processo Civil e autoriza que o juiz ou Relator do recurso ou de procedimento de competência originária dos Tribunais, as partes, Ministério Público ou Defensoria Pública requeiram a instauração do incidente quando houver, simultaneamente, efetiva repetição de processos que contenham controvérsia sobre a mesma questão unicamente de direito e risco de ofensa à isonomia e à segurança jurídica. Ou seja, o referido incidente foi o mecanismo criado pelo novo CPC para julgar casos idênticos, já existentes ou futuros, de maneira única, idêntica e vinculante, sendo, portanto, metodologia de construção de precedentes judiciais.

Sobre esse novo procedimento, informam Luiz Guilherme Marinoni e Daniel Mitidiero:

É bem intencionada sua previsão, na medida em que visa a promover a segurança jurídica, a confiança legítima, a igualdade e a coerência da ordem jurídica mediante julgamento em bloco e fixação de tese a ser observada por todos os órgãos do Poder Judiciário na análise da questão apreciada.(MARINONI; MITIDIERO, 2010, p. 178). 
O referido incidente apresenta fortes influências do direito alemão ${ }^{3}$ e do direito norte-americano, com o objetivo de resolver, de uma vez por todas, o nosso problema de morosidade da Jurisdição, criando um sistema de julgamento de massa, em que um único feito é analisado e o seu resultado é aplicado a todos os outros casos, atuais e futuros, que tratem de idênticas questões de direito.

Trata-se de uma tentativa de buscar maior previsibilidade dos julgados por meio da padronização decisória, o que demonstra claramente uma predisposição de utilização no direito brasileiro das tendências do common law, ou seja, um significativo aumento da relevância dos precedentes judiciais como fonte do direito. Apesar disso, vale ressaltar que os precedentes, "como estão sendo criados e compreendidos/aplicados não são nem precedentes nos moldes do common law, nem jurisprudência, porque prescindem de uma necessária reiteração de julgados no mesmo sentido" (ROSSI, 2015, p. 154).

Sobre tal procedimento, o novo CPC estabelece que poderá ser instaurado, de ofício, pelo juiz ou Relator (ou seja, decisão monocrática do relator, sendo dispensado o julgamento colegiado), a pedido das partes, do MP ou da Defensoria Pública (art. 977).

No caso do Incidente de Resolução de Demandas Repetitivas, não é necessário que exista multiplicidade de julgados em sentidos diversos para que se chegue à construção de um precedente, bastando que haja multiplicidade de casos idênticos, o que ocasionará risco de julgamentos distintos, o que, segundo o novo CPC, poderia ocasionar ofensa à isonomia e à segurança jurídica.

Após suscitado o incidente, o feito será transferido para o órgão competente para o julgamento, que será determinado pelo regimento interno de cada tribunal, o qual será responsável, inicialmente, por analisar a admissibilidade do incidente e, em seguida, por fixar a tese jurídica, já julgando o caso (recurso, remessa necessária ou procedimento originário) em que o incidente foi suscitado.

Sendo admitido o incidente, serão suspensas as outras demandas idênticas que tramitem sob a competência territorial do órgão julgador, sendo que essa suspensão deverá

\footnotetext{
${ }^{3}$ Em 16.08.2005, com publicação em 19.08.2005 e entrada em vigor em 01.11.2005, passa a fazer parte do ordenamento alemão a "Gesetz über Musterverfahren in kapitalmarktrechtlichen Streitigkeiten", ou "Lei sobre procedimentos-modelo para contencioso em mercado de capitais", abreviada como Kapitalanleger Musterverfahrensgesetz (KapMug). As chamadas "causas pilotos" ou, ainda, "processos-teste”, se caracterizam pela escolha de uma ou mais causas similares para serem julgadas, sendo que a partir da solução encontrada nessas causas, os demais casos são solucionados de forma uniforme, ou seja, "uma ou algumas causas que, pela similitude na sua tipicidade, são escolhidas para serem julgadas inicialmente, e cuja solução permite que se resolvam rapidamente todas as demais.
} 
durar por um ano, salvo decisão fundamentada do relator em sentido contrário, prazo esse em que deverá ser julgado o incidente. Caso decorra o prazo sem julgamento do incidente, os feitos sobrestados voltarão a tramitar normalmente.

É necessário destacar uma relevante novidade trazida pelo incidente em questão, que consiste na ampliação da participação das partes interessadas, que, ao contrário do que acontecia nos procedimentos de litigância de massa do CPC/73 (recursos extraordinário e especial repetitivos), não se restringe somente às partes vinculadas ao recurso paradigmático.

Assim, o novo texto é elogiável no tocante à ampliação do debate em tais incidentes, prevendo expressamente que o relator deverá ouvir as partes e os demais interessados, incluindo outras pessoas, órgãos e entidades com interesse na controvérsia, ainda estabelecendo a possibilidade de instrução do incidente com depoimentos de pessoas com experiência e conhecimento na matéria, a serem ouvidas em audiência pública.

É o que prevê o art. 983:

\begin{abstract}
Art. 983. O relator ouvirá as partes e os demais interessados, inclusive pessoas, órgãos e entidades com interesse na controvérsia, que, no prazo comum de 15 (quinze) dias, poderão requerer a juntada de documentos, bem como as diligências necessárias para a elucidação da questão de direito controvertida, e, em seguida, manifestar-se-á o Ministério Público, no mesmo prazo.

$\S 1^{\circ}$ Para instruir o incidente, o relator poderá designar data para, em audiência pública, ouvir depoimentos de pessoas com experiência e conhecimento na matéria.

$\S 2^{\circ}$ Concluídas as diligências, o relator solicitará dia para o julgamento do incidente.
\end{abstract}

A despeito de já ser significativa essa discreta ampliação do debate, tal reforma legislativa não é suficiente para adequar o procedimento de litigância de massa à perspectiva democrática.

Por fim, após julgado o incidente, a tese jurídica nele firmada será, obrigatoriamente, aplicada a todos os casos, pendentes de julgamento ou futuros, sejam eles individuais ou coletivos, que versem idêntica questão de direito (art. 985). Caso o julgador deixe de aplicar o entendimento consolidado pelo incidente, será cabível reclamação, nos termos do art. 988, IV, do novo CPC.

\title{
4 CRÍTICA SOBRE O CONCEITO DE SEGURANÇA JURÍDICA
}




\title{
INCIDENTE DE RESOLUÇÃO DE DEMANDAS REPETITIVAS: UM BREVE ESTUDO SOBRE OS CONCEITOS DE SEGURANÇA JURÍDICA E ISONOMIA
}

De uma análise do sistema de precedentes, notadamente do procedimento adotado no Incidente de Resolução de Demandas Repetitivas e seus efeitos, verifica-se que, para o legislador, segurança jurídica significa controlar o comportamento dos jurisdicionados diante da total previsibilidade do entendimento jurisprudencial, e isonomia significa garantir que todos os jurisdicionados terão julgamentos idênticos diante de idênticas situações fáticas. Todavia, é preciso aprofundar tais conceitos.

Sobre a busca da segurança jurídica por meio da estabilização da jurisprudência, consta da Exposição de Motivos do Anteprojeto do novo CPC:

\begin{abstract}
O novo Código prestigia o princípio da segurança jurídica, obviamente de índole constitucional, pois que se hospeda nas dobras do Estado Democrático de Direito e visa a proteger e a preservar as justas expectativas das pessoas.

Todas as normas jurídicas devem tender a dar efetividade às garantias constitucionais, tornando "segura" a vida dos jurisdicionados, de modo a que estes sejam poupados de "surpresas", podendo sempre prever, em alto grau, as consequências jurídicas de sua conduta.

$\mathrm{Se}$, por um lado, o princípio do livre convencimento motivado é garantia de julgamentos independentes e justos, e neste sentido mereceu ser prestigiado pelo novo Código, por outro, compreendido em seu mais estendido alcance, acaba por conduzir a distorções do princípio da legalidade e à própria ideia, antes mencionada, de Estado Democrático de Direito. A dispersão excessiva da jurisprudência produz intranquilidade social e descrédito do Poder Judiciário.

Se todos têm que agir em conformidade com a lei, ter-se-ia, ipso facto, respeitada a isonomia. Essa relação de causalidade, todavia, fica comprometida como decorrência do desvirtuamento da liberdade que tem o juiz de decidir com base em seu entendimento sobre o sentido real da norma. (BRASIL, 2010)
\end{abstract}

A ideia adotada no novo texto legal é a de que "a maior previsibilidade da decisão do Judiciário implicará menos demandas", buscando, assim, alcançar a "segurança jurídica", tanto por meio da "observância da jurisprudência pelos próprios tribunais e a obediência pelos tribunais e juízes inferiores (uniformização)", como, também, pela "criação de obstáculos para impedir mudanças abruptas da jurisprudência (estabilização)" (FRANZÉ, 2013, p. 245).

O conceito de "segurança jurídica" adotado pelo legislador é esclarecido por Hermes Zaneti Junior, que afirma que se trata de "necessidade de previsibilidade, que se desdobra em confiança legítima do cidadão em relação aos órgãos de administração da justiça" (ZANETI JUNIOR, 2016, p. 339).

Verifica-se que, para o legislador, segurança jurídica significa controlar o comportamento dos jurisdicionados diante da total previsibilidade do entendimento jurisprudencial, e isonomia significa garantir que todos os jurisdicionados terão julgamentos idênticos diante de idênticas situações fáticas, distorcendo, pelo que se constata, os conceitos de isonomia e segurança jurídica. 
A partir deste equivocado conceito de segurança jurídica é que se pretende demonstrar que a obrigatoriedade dos precedentes judiciais assume a forma de dominação.

Ao abordar o conceito de segurança jurídica, retoma-se os estudos de Thomas Hobbes, segundo o qual incumbe ao Estado, por força do pacto de sujeição a que os homens se submetem, garantir-lhes a paz e a defesa. O conteúdo filosófico jurídico de Hobbes parte da ideia da busca da conservação humana através de segurança e paz na sociedade.

Thomas Hobbes afirma que os Estados modernos devem se constituir em sistemas de controle de modo a manter a ordem, o que se dá por meio de controle do governo sobre os cidadãos.

Veja-se:

\begin{abstract}
A única maneira de instituir um tal poder comum, capaz de defendê-los das invasões dos estrangeiros e das injúrias uns dos outros, garantindo-lhes assim uma segurança suficiente para que, mediante seu próprio labor e graças aos frutos da terra, possam alimentar-se e viver satisfeitos, é conferir toda sua força e poder a um homem, ou a uma assembleia de homens, que possa reduzir suas diversas vontades, por pluralidade de votos, a uma só vontade. O que equivale a dizer: designar um homem, ou a uma assembleia de homens, como representante de suas pessoas, considerando-se e reconhecendo-se cada um como autor de todos os atos que aquela que representa sua pessoa praticar ou levar a praticar, em tudo o que disser respeito à paz e segurança comuns; todos submetendo assim suas vontades à vontade do representante, e suas decisões a sua decisão. Isto é mais do que consentimento, ou concórdia, é uma verdadeira unidade de todos eles, numa só e mesma pessoa, realizada por um pacto de cada homem com todos os homens, de um modo que é como se cada homem dissesse a cada homem: 'Cedo e transfiro meu direito de governar-me a mim mesmo a este homem, ou a esta assembleia de homens, com a condição de transferires a ele teu direito, autorizando de maneira semelhante todas as suas ações'. Feito isto, à multidão assim unida numa só pessoa se chama Estado, em latim, Civita. (HOBBES, 1998, p. 105).
\end{abstract}

Como esclarece Rosemiro Pereira Leal, a ideia de Hobbes consiste no mito de se conceber o Estado "como aparelho imprescindível (instituição) de unificação pressuposta das vontades a possibilitar a naturalização (notificação) do imaginário fantasístico das multidões a serviço das reinações dos estadistas" (LEAL, 2010, p. 21). Ou seja: trata-se tão somente de um mito para justificar um estado absolutista e despótico (Estado Social).

Ao se transferir para o Estado o poder mítico de assegurar a segurança jurídica, transfere-se também ao julgador o poder de limitar a liberdade dos cidadãos a partir de provimentos judiciais, a partir da previsibilidade de suas decisões. Assim, busca-se uma “jurisdição redentora, pouco importando os níveis de violência a ser praticada para debelar violências" (LEAL, 2010, p. 42). 
O que se denuncia, a partir de tal busca pela segurança jurídica, é que se instaura um Estado absolutista, despótico, repressor. Ao contrário do que é dito na literatura jurídica brasileira, o princípio da segurança jurídica como motivador da estabilização dos sentidos na jurisprudência não se destina ao jurisdicionado, mas somente ao fortalecimento da violência praticada pelo Estado.

Percebe-se que se mantém o Estado Dogmático, filiado à dogmática analítica, “em que a crença na clarividência do decisor prevalece sobre a lei parlamentarizada a pretexto de que a lei é dotada de uma incompletude fatal" (LEAL, 2013, p. 3).

O fundamento argumentativo apresentado por um enunciado firmado em mecanismo de construção de precedente judicial é oferecido à comunidade jurídica como dogma, ou seja, de maneira inquestionável, sendo possível ao julgador e às partes interessadas somente acolher sua aplicação. E, diante de tal situação, uma das questões mais problemáticas dos precedentes refere-se à sua força vinculativa, obrigando a ocorrência de situações como o julgamento limitar de improcedência, sem que haja qualquer oportunidade argumentativa.

Segundo Roberta Maia Gresta, o novo Código prioriza "o pronunciamento da cúpula do sistema em lugar do amplo debate processual", o que leva à inversão da "ordem de fatores da formação da cultura jurídica e, por conseguinte, subverte o processo como instituição democrática" (GRESTA, 2012, p. 12.635). Gresta acrescenta, ainda, que a redução do "campo

de atuação da parte para demonstrar em juízo que, à luz da norma, sua conduta deve produzir determinado resultado", faz com que também seja reduzida a "certeza e a previsibilidade de que sejam reconhecidos os mesmos efeitos a comportamentos semelhantes" (GRESTA, 2012, p. 12.643). Dessarte, alcança-se uma falsa segurança jurídica, garantida tão somente pela certeza de que os julgamentos semelhantes terão julgamentos idênticos, mas não se garante que a construção e, muito menos, a aplicação destes provimentos judiciais ocorrerá em observância ao devido processo constitucional

Rosemiro Pereira Leal, partindo do estudo de Derrida, denuncia a violência da imposição da lei, sustentada pelo "fundamento místico da autoridade", apontando a total ausência de "um núcleo teórico como fundamento a balizar a construção da lei” (LEAL, 2010, p. 99). Essa violência, imposta pela vontade da autoridade, não se limita somente à lei, mas também é perceptível pela imposição dos julgados dos tribunais superiores, que criam precedentes, julgam recursos por eles escolhidos como paradigmas, criam súmulas 
vinculantes, estabelecendo, portanto, "teses" que devem ser seguidas pelos outros tribunais, pelo simples fato de terem sido impostos por uma autoridade.

Desse modo, é possível constatar que a aplicação dos entendimentos construídos pelos Tribunais Superiores se dá pela dominação exercida pelos julgadores desses tribunais sobre aqueles que exercem a função jurisdicional em outros tribunais hierarquicamente inferiores, bem como sobre o povo, que passa a ter sua atuação controlada e prevista pelos enunciados judiciais.

\title{
5 CRÍTICA SOBRE O CONCEITO DE ISONOMIA
}

Também se verifica um total descuido do legislador no que tange à isonomia, uma vez que tal princípio institutivo do processo não pode ser tratado a partir do conceito simplista de garantir a todos tratamento igualitário, o que, diante dos mecanismos de construção de precedentes, se traduz em garantir a todos os jurisdicionados provimentos idênticos.

A isonomia consiste na garantia constitucional de que as partes serão tratadas no procedimento de forma igualitária, sem que se limite indevidamente a participação de nenhuma delas e também sem que nenhuma parte tenha qualquer privilégio em detrimento da outra. Possui estreita correlação com o princípio do contraditório, tendo em vista que "não há contraditório desenvolvido sem observância da simétrica paridade" (FONSECA, 2000, p. 19)' ou seja, a igualdade de tratamento processual das partes é essencial para garantir o efetivo contraditório.

Assim, isonomia pode ser compreendida como parte da essência do contraditório, sendo a garantia fundamental responsável pela simétrica paridade de participação no processo.

Para Fix-Zamudio:

\begin{abstract}
Este princípio fundamental de qualquer regime democrático e que, em termos gerais, implica igualdade de oportunidades, transcendeu a esfera processual em várias direções, e uma das mais importantes é o chamado caráter dialético do processo ou "contraditório", o qual significa que qualquer procedimento jurisdicional requer a intervenção equilibrada das partes essenciais que apresentem interesses contrapostos, e condensa a frase audiatur et altera pars. 4
\end{abstract}

\footnotetext{
${ }^{4}$ No original: "Este princípio fundamental de todo regímen democrático y que en términos generales implica la igualdad de oportunidades há transcendido el ambito procesal em varias direcciones, y uma de las mas importantes es el llamado caracter dialético del proceso o "contraditório", el cual significa que todo procedimiento jurisdicional requiere de la intervención equilibrada de las partes esenciales que poseen intereses
} 
Todavia, sobre as recentes reformas do direito processual, tem-se que:

O maior risco que essas reformas trazem é que, no afã de implantar um sistema de precedentes em nosso ordenamento - porque tal sistema supostamente geraria maior isonomia e celeridade processual -, estas reformas acabam por suprimir verdadeiros direitos e garantias fundamentais do cidadão, na medida em que ignoram a flexibilidade ínsita ao sistema de precedente do common law. (ABBOUD, 2012, p. 493).

Verifica-se que, apesar da promessa trazida pelo novo Código de Processo Civil de garantia da isonomia por meio da construção de precedentes judiciais, o conceito de isonomia não é, de fato, pesquisado e demarcado, ocasionando uma confusão do legislador quanto a este princípio.

Considerando como ponto de partida do estudo do conceito de isonomia a Teoria Neoinstitucionalista do Processo, tem-se que a "isonomia é princípio-norma que rege a atuação dos sujeitos do processo quanto à igualdade argumentativa na formação do discurso estrutural do procedimento de produção e aplicação do direito" (LEAL, 2005, p. 81). Segundo Rosemiro Pereira Leal, no Estado Democrático de Direito, a isonomia processual não se limita a um reconhecimento do direito à diferença, devendo ser compreendida como um direito das partes à igualdade argumentativo-procedimental na defesa e reconhecimento de seus direitos, o que a torna essencial para a construção e aplicação normativa (LEAL, 2005, p. 79).

Dessarte, esclarece o referido autor:

A isonomia, como princípio legal, autodiscursivo e legitimante de validade da
instituição do devido processo constitucional, já impõe a igualdade procedimental a
ensejar a execução de igualdades fundamentais de direitos dos desiguais e diferentes
já decididos, como líquidos, certos e exigíveis, no plano da normatividade
constituinte e, por conseguinte, protegidos pela invulnerabilidade do instituto da
coisa julgada constitucional que, na democracia, é estabilizadora dos direitos
fundantes da constitucionalidade democrática desde as etapas instituinte e
constituinte de sua criação normativa até sua efetiva execução jurisdicional (LEAL,
2005, p. 84.)

De forma essencial para a compreensão do problema a ser tratado no presente estudo, também defende Rosemiro Pereira Leal que a "a isonomia supõe três vertentes de reflexão: isotopia, isomenia e isocrítica”. Ou seja, compreende que esta igualdade de participação dos jurisdicionados deve ocorrer nos âmbitos constituinte, instituinte e instituído" (LEAL, 2006).

contrapostos, y se condensa el la frase: audiatur et altera pars". FIX-ZAMUDIO, Hector. Constituición y Proceso Civil em Latinoamérica. México: Instituto de Investigaciones Juridicas, 1974, p. 63/64. 
Para fins de discussão acerca da construção de precedentes judiciais, interessa, especialmente, a noção de isomenia, que consiste na igual possibilidade de interpretação da norma, não limitando tal atividade somente ao julgador, mas sim a todos os interessado (LEAL, 2016, p. 99). Desse modo, “a isomenia assegura direito igual de interpretação jurídica para todos, sendo referente lógico-jurídico que passa pela constitucionalidade"'(SALES, 2012, p. 159).

Assim, esclarece Rosemiro Pereira Leal:

O espaço-político (isegoria) de criação do direito só será continente democrático se já assegurados os conteúdos processuais dialógicos da isonomia - que são a isotopia, isomenia e isocrítica - em que haja, portanto, em sua base decisória, igualdade de todos perante a lei (isotopia), igualdade de todos de interpretar a lei (isomenia) e igualdade de todos de fazer, alterar ou substituir a lei (isocrítica). (LEAL, 2016, p. 99).

Sobre a interpretação do texto legal no Estado Democrático de Direito, Dhenis Cruz Madeira afirma:

No Estado Democrático de Direito, tanto a interpretação quanto a hermenêutica rejeitam fórmulas, brocardos ou regras predeterminadas de julgamento, visto que somente a normatividade constitucional é capaz de conduzir e demarcar o conteúdo do provimento, ainda assim, sob a condição de participação dialógica dos destinatários da norma num médium linguístico processualizado.

A interpretação dos textos de lei deve ser feita de forma compartilhada, haja vista que a legitimação dos provimentos passa pela participação simétrica dos destinatários e, como óbvio, pela análise dos argumentos ventilados. (MADEIRA, 2009, p. 41).

Todavia, ao se transferir somente para os Tribunais a possibilidade de uma interpretação legítima do direito, faz-se com que se estabeleça a dominação por meio da manipulação dos sentidos:

\footnotetext{
Analisados, um a um, todos os modos de dominação que o homem inventou ao longo dos séculos para relacionar-se com o seu próximo, nenhum é mais eficiente que o da manipulação dos sentidos. Aquele que manipula os sentidos do discurso transforma-se no árbitro todo-poderoso da comunidade para a qual define o que venha a ser valor e antivalor; é ele que assinala os objetivos a serem perseguidos pelo grupo, dita as regras de comportamento que hão de dirigir a ação singular dos indivíduos na tentativa de realização de seus valores, pune e recompensa. Pois como os mitos sempre demonstraram, só o que sabe quer, só o que sabe pode, só o que sabe faz." (LOPES, 1978, p. 5).
}

Assim, “é inevitável a manipulação (monopólio) do sentido normativo pelo Estado

Juiz, tornando-se não refutável o saber-poder da autoridade intérprete" (LEAL, 2014, p. 250).

Esclarece Rosemiro Pereira Leal: 
Aqui, o intérprete prodigiosamente desenvolve uma compreensão por argumentos (cuja lógica e teoria da linguagem não se explicitam) que se rotulam linguísticos e sistemáticos habilmente manejáveis pela experiência e talento (razão) pseudocientífico do julgador. (LEAL, 2016, p. 300).

Isto considerando, alcança-se que os estudos sobre precedentes judiciais, de forma geral, têm por fundamento a necessidade de adotar os entendimentos firmados pelos Tribunais Superiores, em razão da necessidade de uniformizar a jurisprudência e garantir segurança jurídica.

Diante de tais considerações, verifica-se que a pretensão de alcançar isonomia pela simples busca de resultados idênticos para casos idênticos não se mostra compatível com as diretrizes do Estado Democrático de Direito, já que não considera o igual direito de participação na construção do mérito, nem mesmo o igual direito de interpretação da norma.

\section{CONSIDERAÇÕES FINAIS}

Diante das considerações trazidas no presente trabalho, pode-se perceber que a implementação do Incidente de Resolução de Demandas Repetitivas não se coaduna com o paradigma do Estado Democrático (não-dogmático) de Direito.

A inserção de tal procedimento no Direito Brasileiro não busca, como se verifica da Exposição de Motivos, melhorar a previsibilidade da prestação da atividade jurisdicional, mas busca alcançar resultados rápidos, idênticos, que acabarão por iniciar o acesso à jurisdição, quando conflitante com o interesse da parte autora, ou, ainda, a ampla defesa e contraditório, em todos os casos.

Apesar de tal técnica de julgamento por amostragem ser aplaudida pela maior parte da literatura jurídica, observa-se que ela ocasiona diversos problemas gravíssimos, principalmente em relação à efetividade das garantias fundamentais do processo, constitucionalmente previstas, sendo, na verdade, uma ameaça à democratização do processo, a partir de compreensões completamente equivocadas e simplistas dos conceitos de segurança jurídica e de isonomia.

Ao compreender a segurança jurídica como instrumento de fortalecimento do Poder estatal e, consequentemente, da atividade jurisdicional, verifica-se que tal instituto se direciona ao exercício do controle do povo, enquanto o processo democrático deve servir de mecanismo de controle do Estado pelo povo. 
Ainda ocorre uma tendência de aplicação de precedentes como forma de fundamentar as decisões judiciais, como se tal aplicação dispensasse qualquer outro fundamento, como se fosse suficiente fundamentar uma decisão com o simples argumento de que o mesmo ou outro Tribunal já decidiu da mesma forma.

No que tange à isonomia, viu-se que esse conceito extrapola a noção simplista de tratamento igualitário de todos, devendo, na perspectiva democrática, abranger o igual direito de participação e de interpretação, não sendo esses pontos objeto de preocupação do legislador ao mencionar o risco à isonomia como fundamento para a instauração do Incidente de Resolução de Demandas Repetitivas.

Isso porque, adotado determinado entendimento pelos Tribunais, mediante a utilização de mecanismos de criação de precedentes judiciais, este deve ser obrigatoriamente aplicado nos casos futuros, sem possibilidade de se interrogar sua validade ou legitimidade democrática. Reforça-se, portanto, a possibilidade de manipulação dos sentidos pelo julgado, o qual, tem a autorização (legal, tradicional e/ou carismática) para instituir dogmas inquestionáveis. E tal prática não pode ser admitida no Estado Democrático de Direito, uma vez que este se pretende "não dogmático".

Transfere-se para o julgador o poder de dominar a sociedade pelo monopólio interpretativo do direito, excluindo-se, tal como proposto pelos positivistas, a isomenia do conceito de isonomia, impossibilitando o igual direito de interpretação e substituindo-o pelo direito de interpretação idêntica.

Percebe-se que tal obrigatoriedade dos precedentes exerce uma ampla dominação, uma vez que não há só o controle dos jurisdicionados por meio da carga de violência trazida pela incessante busca da segurança jurídica, e do julgador, impedindo que este decida de forma contrária à "orientação" dos Tribunais. O controle, na verdade, é direcionado ao devido processo, impedindo este instituto de existir. 


\section{REFERÊNCIAS}

ABBOUD, Georges. Precedente judicial versus Jurisprudência dotada de efeito vinculante: A ineficácia e os equívoco das reformas legislativas na busca de uma cultura de precedentes. In: WAMBIER, Teresa Arruda Alvim (Coord.). Direito Jurisprudencial. São Paulo: Revista dos Tribunais, 2012.

BRASIL, 2010. Anteprojeto Do Novo Código De Processo Civil. Senado Federal. Brasília. Disponível em <https://www.senado.gov.br/senado/novo cpc/pdf/Anteprojeto.pdf> Acessado em 13 jul 2017.

BRASIL, 2015. Lei no 13.105, de 16 de março de 2015. Código de Processo Civil. Disponível em <http://www.planalto.gov.br/ccivil_03/_ato2015-2018/2015/lei/113105.htm> Acessado em 13 jul 2017.

FARIA, Gustavo de Castro. A Jurisprudencialização do Direito: Reflexões no Contexto da Processualidade Democrática. Belo Horizonte: Arraes, 2012.

FONSECA, Rodrigo Rigamonte. Isonomia e Contraditório na Teoria do Processo. In: LEAL, Rosemiro Pereira (coord.) Estudos Continuados de Teoria do Processo. Vol. 1. Porto Alegre: Síntese, 2000

FRANZÉ, Luís Henrique Barbante; SOUZA, Tiago Clemente. Eficácia do Sistema Recursal no Projeto de Lei no 8.046/2010. In: SILVA, Nelson Finotti; FRANZÉ, Luís Henrique Barbante; GARCIA, Bruno Pinotti (orgs.). Reflexões sobre o Projeto do Novo Código de Processo Civil. Curitiba: CRV, 2013.

GRESTA, Roberta Maia. Introdução aos Fundamentos da Processualidade Democrática. Rio de Janeiro: Lumen Juris, 2014.

HOBBES, Thomas. O Leviatã ou Matéria, Forma e Poder de um Estado Eclesiástico e Civil. São Paulo: Nova Cultura, 1998.

LEAL, Rosemiro Pereira. A Principiologia Jurídica do Processo na Teoria NeoInstitucionalista. Revista da Faculdade Mineira de Direito. № 2/2006. Disponível em: http://www.fmd.pucminas.br/Virtuajus/2_2006/Docentes/pdf/Rosemiro.pdf. Acesso em 28 maio 2017.

LEAL, Rosemiro Pereira. A Teoria Neoinstitucionalista do Processo: Uma Trajetória Conjectural . Belo Horizonte: Arraes, 2013.

LEAL, Rosemiro Pereira. Processo como Teoria da Lei Democrática. Belo Horizonte: Fórum, 2010.

LEAL, Rosemiro Pereira. Relativização Inconstitucional da Coisa Julgada: Temática Processual e Reflexões Jurídicas. Belo Horizonte: Del Rey, 2005. 
LEAL, Rosemiro Pereira. Teoria Geral do Processo: Primeiros Estudos. Rio de Janeiro: Forense, 2014.

LOPES, Edward. Discurso, Texto e Significação. São Paulo: Cultrix, 1978.

MADEIRA, Dhenis Cruz. Processo de Conhecimento e Cognição. Curitiba: Juruá, 2009

NUNES, Dierle. A Litigância de Interesse Público e as Tendências "não Compreendidas" de Padronização Decisória. Revista de Processo, Vol. 199, setembro/2011.

NUNES, Dierle. Precedentes, Padronização Decisória Preventiva e Coletivização - Paradoxos do Sistema Jurídico Brasileiro: Uma Abordagem Constitucional Democrática. WAMBIER, Teresa Arruda Alvim. Direito Jurisprudencial. São Paulo: Revista dos Tribunais, 2012. P. 263.

ROSSI, Júlio César. Precedente à Brasileira: A Jurisprudência Vinculante no CPC e no novo CPC. São Paulo: Atlas, 2015

SALES, Ana Flávia. Teorias de direito e direito processual democrático: incursões tópicojurídicas pela teoria neoinstitucionalista do processo. Dissertação de Mestrado. Belo Horizonte, 2012

ZANETI JUNIOR, Hermes. O Valor Vinculante dos Precedentes: Teoria dos precedentes normativos formalmente vinculantes. Salvador: Juspodivm, 2016. 